\title{
La República y su recepción
}

\author{
FRANCISCO L. LISI \\ Universidad Carlos III de Madrid \\ Instituto de Estudios Clásicos "Lucio Anneo Séneca" \\ flisi@hum.uc3m.es
}

La República es uno de los dos diálogos mayores del corpus platónico y el que defiende la tesis más famosa del pensador ateniense, la unión de conocimiento y poder que se concreta en el gobierno absoluto de un reducido grupo de filósofos que ejercen alternativamente una monarquía temporal. La aspiración a unir conocimiento y poder ha tenido una larga recepción en el pensamiento político occidental que llega hasta nuestros días. La crítica a la idea, que se encuentra en la base de la democracia, de que cualquiera puede ejercer el mando es uno de los puntos centrales de la República y se encuentra aún sometida a crítica ${ }^{1}$.

Esto no significa que el diálogo se limite a ese tema, puesto que, además de ésta, presenta varias tesis que son especialmente provocativas. En primer lugar, la división de la sociedad en dos estamentos o castas, los gobernantes y los gobernados, que por la descripción que hace Platón parecen ser hasta razas diferentes, ha encontrado una fuerte oposición buena parte de la filosofía política moderna. Entre los gobernantes existe también una división importante: los guardianes y los filósofos. Aunque ambos tienen una vida en común, los filósofos tienen acceso a una educación superior y se distinguen en todo momento de los guardianes a los que también gobiernan de manera absoluta. Es verdad que en el siglo XX esta idea ha reaparecido transformada en las corrientes ideológicas relacionadas con formas diversas de totalitarismo a través de concepciones como el partido a secas o el partido como vanguardia del proletariado que suponen una estricta subordinación de los brazos controladores de la sociedad al reducido grupo de dirigentes que a través de sus normas intentan dirigir la vida de los habitante de un país. Los defensores liberales y democráticos del divino Platón se han visto impulsados a relativizar con diversas estrategias la defensa a ultranza de este principio que hace el pensador ateniense.

La tesis del comunismo que impera en la casta gobernante ha despertado interés, simpatía y escándalo. Si bien los padres del movimiento contestatario más importante de los últimos dos siglos, Karl Marx y Friedrich Engels, buscaron diferenciarse del comunismo platónico y lo consideraron un comunismo de usufructo, sus conti-

\footnotetext{
${ }^{1}$ Véase, p. ej., el reciente trabajo de J. Brennan, Against democracy, Princeton-Oxford 2016.
}

ПНГН / F O N S II (2017), 5-7

ISSN 2445-2297 www.uc3m.es/pege
F.L. Lisi, La República y su recepción DOI https://doi.org/10.20318/fons.2017.3461 
nuadores fueron abandonando la sana costumbre de leer a sus clásicos hasta llegar a su obvia indigencia intelectual actual y fueron viendo cada vez con mayor simpatía el comunismo platónico, tal vez impulsados por el prestigio de la figura del pensador ateniense que más deslumbra cuanto más se lo ignora, dado que es sin duda un hito determinante en la tradición occidental. De esta manera fueron abrazando un ideal de comunismo que se corresponde más con el que Platón predica para sus gobernantes que con las posiciones de Marx y Engels. Lógicamente, extendieron el comunismo de usufructo a toda la sociedad y la abolición absoluto de la propiedad privada, algo que en la República no queda establecido de manera expresa. A pesar de su nombre, el comunismo marxista no propone un comunismo propiamente dicho, dado que no propugna la abolición propiedad privada per se, sino que preconiza sólo la propiedad pública de los medios de producción, algo radicalmente diferente.

Otro elemento que ha escandalizado a lo largo de los siglos es la disolución de la familia y la propiedad común de las mujeres y los hijos, una proposición fuertemente criticada por Aristóteles en el segundo libro de la Política (3, 1261b16-4,1262b35). A pesar de que a partir de los movimientos del 68 y sus recientes revivals este aspecto ha contado y cuenta con simpatizantes, se trata de una característica que difícilmente pueda ser extendida a toda la sociedad por razones obvias, tal como lo evidencia con brillantez Aristófanes en Las asambleístas. Por otro lado, en el caso de la República, la propiedad en común de las mujeres no significa en absoluto la posibilidad de usufructo sexual a voluntad por los varones. Las relaciones son reproductivas; bien entendido: reproductivas, y están sometidas a una estricta regulación dependiendo de las supuestas capacidades de unos y otros en una cuidada planificación eugénica (Resp. V 458d9-e1, 460c3-5, d9-10, et passim).

La aparente igualdad entre varones y mujeres, otro aspecto apreciado por algunos exégetas también tiene claras limitaciones. Las mujeres se encuentran en un régimen de propiedad comunal (IV 449c3-5, d4-5; V 457c10-d3; et passim), no pueden decidir libremente y según su libre arbitrio con quién aparearse y están a disposición de los varones, especialmente los más valientes, para mantener relaciones sexuales con ellos ( $c f$. V, 459d7-460b6). La naturaleza de la mujer y del varón es semejante, pero

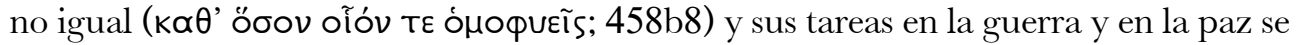
adaptarán a su naturaleza más débil que la del varón (456a10-11, 457a9-10). Entre las limitaciones naturales se encuentran la gestación de los vástagos y su amamantamiento. Es de suponer, por tanto, que el peso de la guerra lo llevarán los varones y la excelencia guerrera es, junto a la filosofía, un requisito indispensable para llegar a ser rey de Calípolis (VIII 543 a1-6). El lenguaje de Sócrates traiciona siempre que piensa en los varones como poseedores y sujetos y en las mujeres y los niños como posesiones y objetos, a pesar de toda la aparente igualdad entre varones y mujeres que podría de- 
ducirse de un análisis parcial de sus expresiones (cf. e. g. IV 423e4-424a2; V 451c4$8)^{2}$.

En el plano político, la implantación de la censura de los poetas ha despertado, como era de esperar, menor simpatía, en especial en los intelectuales contemporáneos. No obstante, ésta es quizás una de las proposiciones que mayor pervivencia ha tenido a lo largo de la historia, no siempre como consecuencia de la lectura de Platón. La implantación de la censura o, mejor, la expulsión de los poetas de la ciudad ofrece, sin embargo, aspectos muy dignos de reflexión en la época de la cultura de masas y de la obvia manipulación de la población a través de la información y la cultura. No obstante, es un aspecto que entra en franca colisión con el principio de libertad de expresión, aunque actualmente hay un debate en ciernes sobre los límites de este derecho, en especial en lo que atañe a la su relación con la privacidad de las personas. Estos y otros temas relacionados con ellos han sido objeto de una intensa polémica desde el siglo XIX. En especial, la utilización de los totalitarismos del texto de Platón ha puesto a la República en el foco de atención de la filosofía política contemporánea.

Si bien estos temas muestran la actualidad política de los asuntos tratados en el diálogo platónico, su importancia no se reduce a ellos, dado que la finalidad principal del diálogo es demostrar que el hombre justo es en todas las posibles circunstancias más feliz que el injusto. Para ello, Platón no desarrolla sólo una teoría del estado y de la justicia, sino también una doctrina del alma, un plan educativo y hace la exposición más detallada en su obra de los principios de la realidad, en especial del principio supremo, la Idea del Bien. Como es sabido, esta doctrina desarrollada en los libros centrales por medio de tres alegorías, ha sido también objeto de una larga controversia sobre las características del principio, si es trascendente a las Ideas, si se identifica con lo Uno, qué relación tiene con los agrapha dogmata, etc. El presente número de ПНГН/FONS ofrece una selección de artículos sobre un texto que sigue vigente y es uno de los fundamentos de la tradición occidental y universal.

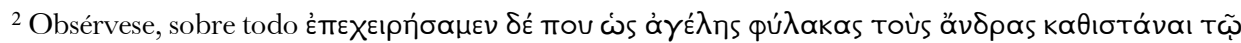

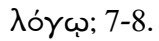

